\title{
The Wood-Based Biorefinery: A Source of Carbon Fiber?
}

\author{
Göran Gellerstedt*, Elisabeth Sjöholm and Ida Brodin
}

Innventia AB, Box 5604, SE-11486 Stockholm, Sweden

\begin{abstract}
In this mini-review, various attempts to make carbon fiber from lignins are discussed. The replacement of construction steel in cars and trucks with a much lighter carbon fiber-based composite will ultimately result in more fuelefficient vehicles. To replace the precursors of carbon fiber, polyacrylonitrile (PAN), or other non-renewable materials such as pitch, by cheap (kraft) lignin, a comprehensive understanding of the physical and chemical characteristics of lignin and the development of methods for its homogeneous large-scale production must be achieved.
\end{abstract}

Keywords: Black liquor, carbon fiber, kraft lignins, oxidative stabilization, strength properties, thermal analysis.

\section{THE CHALLENGE}

Carbon fiber $(\mathrm{CF})$ is a relatively new high-strength lightweight material that was originally developed for the aerospace industry. Applications of CF composites take advantage of its strength, stiffness, low weight, fatigue characteristics, lack of corrosion and heat insulation. Modern aircrafts, engineering industries and sporting goods producers use large quantities of CF. Currently, a total of about 50,000 tons of $\mathrm{CF}$ is annually used world-wide, and the market is increasing by about $10 \%$ per year with the main producers being from Japan and the US. The major part of CF (> 90\%) is produced by heat treatment and pyrolysis of polyacrylonitrile (PAN), a synthetic material made from petroleum feedstock; however petroleum- or coal-based pitch or viscose fiber can also be used. There are certain drawbacks to the current precursors, such as the high price of PAN and its slow graphitization, the uneven quality of pitch and the comparatively low strength of viscose-based CF. An improvement in the mechanical strength of synthetic fibers requires enhanced purity of the individual starting materials.

The automobile industry is seeking a light structural material to considerably reduce vehicle weight thereby increasing the fuel economy irrespective of the type of propulsion (internal combustion, fuel cell or battery powered) without compromising vehicle performance, safety, recyclability or cost. The main obstacle to large-scale use of CF in the automobile industry is its high cost, which is roughly 20 times higher than that of steel. According to estimates made by Oak Ridge National Laboratory, USA, a replacement of $>60$ $\%$ of the ferrous metals in automobiles by CF composites could reduce the overall weight by $\sim 40 \%$ and the fuel consumption by $>20 \%$ [1]. However, the production cost of CF must drop from its current cost of $\sim 22$ USD per $\mathrm{kg}$ to $\sim 11$ USD per $\mathrm{kg}$ to be considered as an affordable option. Thus, the development of low-cost carbon fiber would allow for

*Address correspondence to this author at the Innventia AB, Box 5604, SE11486 Stockholm, Sweden; Tel: +46 867670 00; Fax: +46 841155 18;

E-mail: goran.gellerstedt@innventia.com production of $\mathrm{CF}$ composites for large-scale use. Among the alternative carbon sources for CF, lignin is well suited if it can be generated on a large scale and with a constant "quality". Furthermore, since lignin is a renewable biopolymer, sustainable production is also possible.

Lignin is the second most abundant substance in nature and is present in all fibrous plants. A poly-aromatic macromolecule, readily available and comparatively inexpensive, it may fulfill many of the requirements for being a precursor to $\mathrm{CF}$. The kraft (and sulfite to a minor extent) pulping industry produces large quantities of lignin as a byproduct when converting wood into chemical pulp fibers for further conversion to a variety of paper and board products. Lignin is present as an aqueous solution (black liquor) in the process; in most mills, this solution is concentrated by evaporation before being burnt in a recovery boiler to produce the energy necessary for the pulping operation.

\section{THE WOOD-BASED BIOREFINERY}

A future development of processes for biomass utilization may involve a "biorefinery" concept in which wood (biomass) is brought to a mill site and further converted to pulp and paper or, alternatively, to energy, biofuels and chemicals through processes such as prehydrolysis-kraft, organosolv pulping, steam explosion, autohydrolysis or acid hydrolysis. In contrast to the traditional kraft pulping process, the alternative processes are not suitable for making pulp and paper but can be developed for alternative purposes, such as cellulose, hemicelluloses and lignin production. The lignin can be chemically modified either within the process or in a subsequent treatment. In the future, lignin will likely be readily available in large quantities. Although an excellent bio-fuel, new uses of lignin in more high-value-added products are attractive, because the isolation and refining of lignin involve processing steps that can be combined with structural modifications such as membrane fractionation, derivatization and others.

In the transformation from an oil-based to a biomassbased society, the efficient utilization and conversion of 
wood and other biomass into fuel, chemicals and materials are essential. For a long time, the forestry industry has been the most efficient user of biomass and large quantities of pulp are produced annually in mills with highly effective use of wood, chemicals, energy and water. In a large national project, the energy from state-of-the-art Swedish kraft mills, was analyzed and compared to that from a theoretical reference mill, equipped with the best available technology (Fig. 1) [2]. A new mill should be a net producer of energy without sacrificing the production of pulp or wood consumption. Thus, rather than producing excess steam in the mill, the removal of a portion of the dissolved wood polymers should be a viable option also allowing for new product areas (Fig.
2). Such removal could be used for increasing pulp production since the recovery boiler in many mills is operating close to its maximum capacity. Taken with the fact that the market price for pulp is gradually decreasing by about $1-2 \%$ per year, and the simultaneous rapid increase in wood and energy costs, pulp mills are now being forced to develop new business ideas to make a reasonable profit.

Large quantities of kraft lignin could potentially be made available for further conversion to $\mathrm{CF}$ (or other materials/chemicals) through a recently developed process for kraft lignin isolation. In the LignoBoost process, partially evaporated black liquor is acidified with carbon dioxide, filtered,

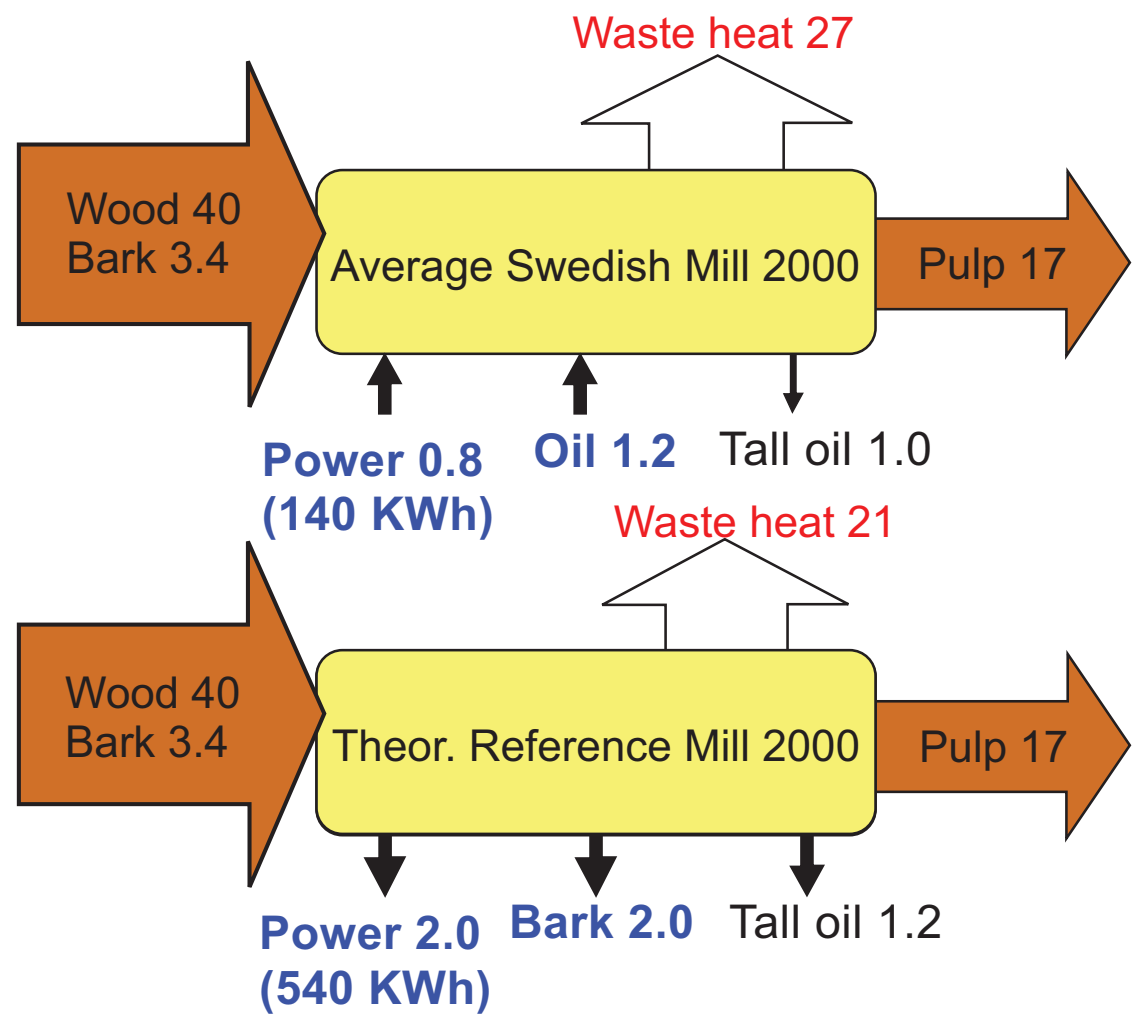

Fig. (1). Energy balance in kraft pulp mills expressed in GJ/ton of pulp; the Swedish average mill in 2000 and a theoretical reference mill equipped with state-of-the-art technology in 2000 [2].
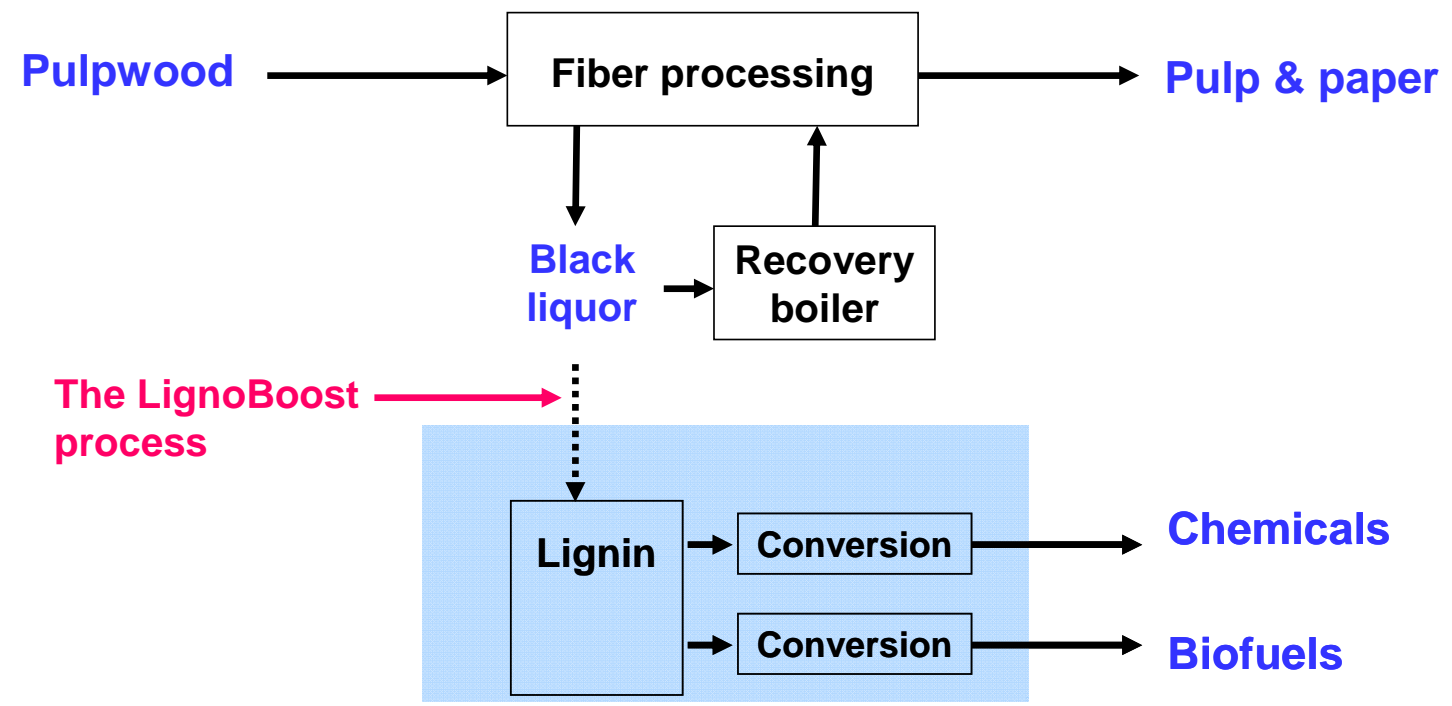

Fig. (2). A future kraft pulp mill with partial withdrawal of lignin according to the LignoBoost process [3]. 
re-slurred in aqueous acid, filtered again and finally washed [3]. The resulting lignin has a high dry content (70\%) and is relatively pure, as shown in Fig. (3). By assuming an average output of $10 \%$ of the available kraft black liquor lignin in European kraft mills, a production of approximately 1.5 million tons of kraft lignin is possible. Since kraft lignins contain $>60 \%$ carbon, a huge quantity of CF could theoretically be produced if suitable technology for conversion from lignin to CF is developed.

\section{CARBON FIBER FROM LIGNIN}

The desirable development of an alternative precursor for $\mathrm{CF}$, based on a renewable material such as lignin, was identified a long time ago. In the 1960s, Kayocarbon fiber, a commercial CF from lignin, was produced by Nippon Kayaku Co in Japan, but it was discontinued in 1973. In this process, the fiber was produced from lignosulfonate, using polyvinyl alcohol added as the plasticizer, and then dry spun $[4,5]$. Starting in the 1990 s, new attempts were made and several different types of lignins were thoroughly investigated as precursors for $\mathrm{CF}$, such as steam explosion lignin, organosolv lignin and kraft lignin.

\section{Steam Explosion Lignin}

The steam explosion process involves heating of the wood (biomass) in the presence of steam to temperatures about $200-220^{\circ} \mathrm{C}$ followed by rapid decompression. The wood is "exploded" and individual fibers and fiber bundles are formed. From hardwoods, a subsequent extraction with organic solvent (e.g., acetone or methanol) or aqueous alkali can be used to isolate lignin in high yields $[6,7]$. By hydrogenolysis of the lignin, subsequent extractions with chloroform and carbon disulfide followed by heat treatment and melt spinning, a "green" fiber was obtained. After thermostabilization in air at $210^{\circ} \mathrm{C}$, the fibers were carbonized at $1000^{\circ} \mathrm{C}$ to yield "general purpose" grade CF [8]. The mechanical properties of these fibers are shown in Table 1 . The same type of lignin subjected to phenolysis rather than hydrogenolysis followed by purification and heat treatment under vacuum at $280^{\circ} \mathrm{C}$ was also melt spun, and the resulting fibers were stabilized in air at $300^{\circ} \mathrm{C}$ and further carbonized at $1000^{\circ} \mathrm{C}$. However, no improvements in the strength properties were observed (Table 1), but the yield of the purified lignin was much higher [9]. Further studies using the steam explosion process to produce lignin suitable for conversion to $\mathrm{CF}$ have been done to investigate several hardwood and softwood species and the influence of the process parameters [10]. Due to the acidic environment, the degradation and condensation reactions taking place in lignin during steam treatment of wood (biomass) proceeds, through a common carbonium ion intermediate. Therefore, the addition of a low molecular mass nucleophile, such as phenol, will compete with internal nucleophilic centers in the lignin, resulting in degradation as the predominant structural change [11].

\section{Organosolv Lignin}

A similar mechanism operates in organosolv pulping, which is the treatment of wood (biomass) with an organic solvent. So far, the most interesting alternatives are ethanol pulping according to the Alcell process and pulping with acetic acid in the presence of a small amount of sulfuric acid or hydrochloric acid $[12,13]$. From both of these processes, the lignin is isolated, purified/modified and subjected to melt spinning. In the presence of polyethyleneoxide (PEO) as a plasticizer, Alcell (hardwood) lignin had an improved spinnability, but the subsequent thermo-stabilization in air had to be done at a very low heating rate to avoid self-fusing of the filaments. After carbonization, the mechanical properties of the $\mathrm{CF}$ were better than those of other types of $\mathrm{CF}$ from organosolv lignins (Table 1) [14].

The spinnability of acetic acid lignin, obtained through acetic acid pulping of birch wood, was improved after a thermal treatment under reduced pressure to modify the lignin structure. Thereby, an increase in average molecular mass was achieved while the content of methoxyl and acetyl groups was kept unchanged. After thermo-stabilization in air at $250^{\circ} \mathrm{C}$ and carbonization at $1000^{\circ} \mathrm{C}, \mathrm{CF}$ with the strength properties shown in Table 1 was obtained [15]. By contrast,

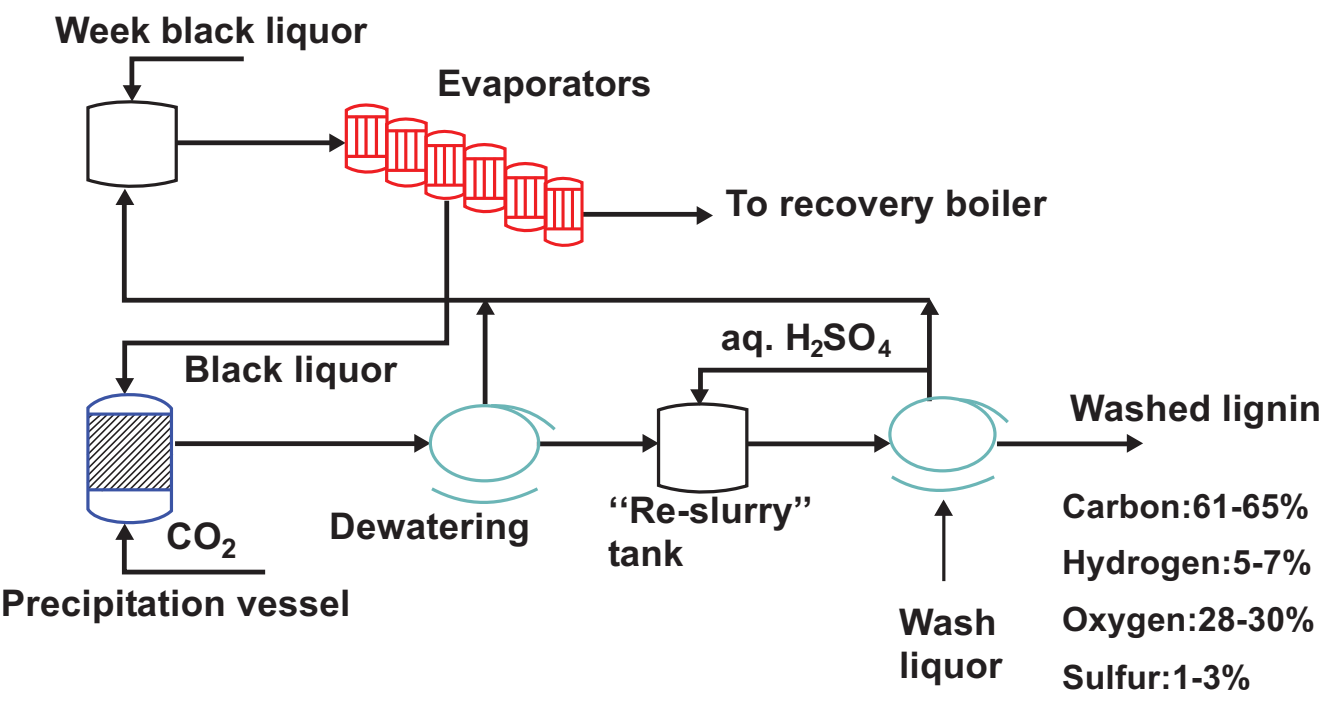

Ash:0.2-0.4\%

Carbohydrates:1-2\%

Fig. (3). The LignoBoost process and composition of the obtained kraft lignin [3]. 
Table 1. Mechanical Properties of Carbon Fibers Made from Lignin Precursor. Measured Fiber Diameters have been Included Since these will Affect the Strength Value

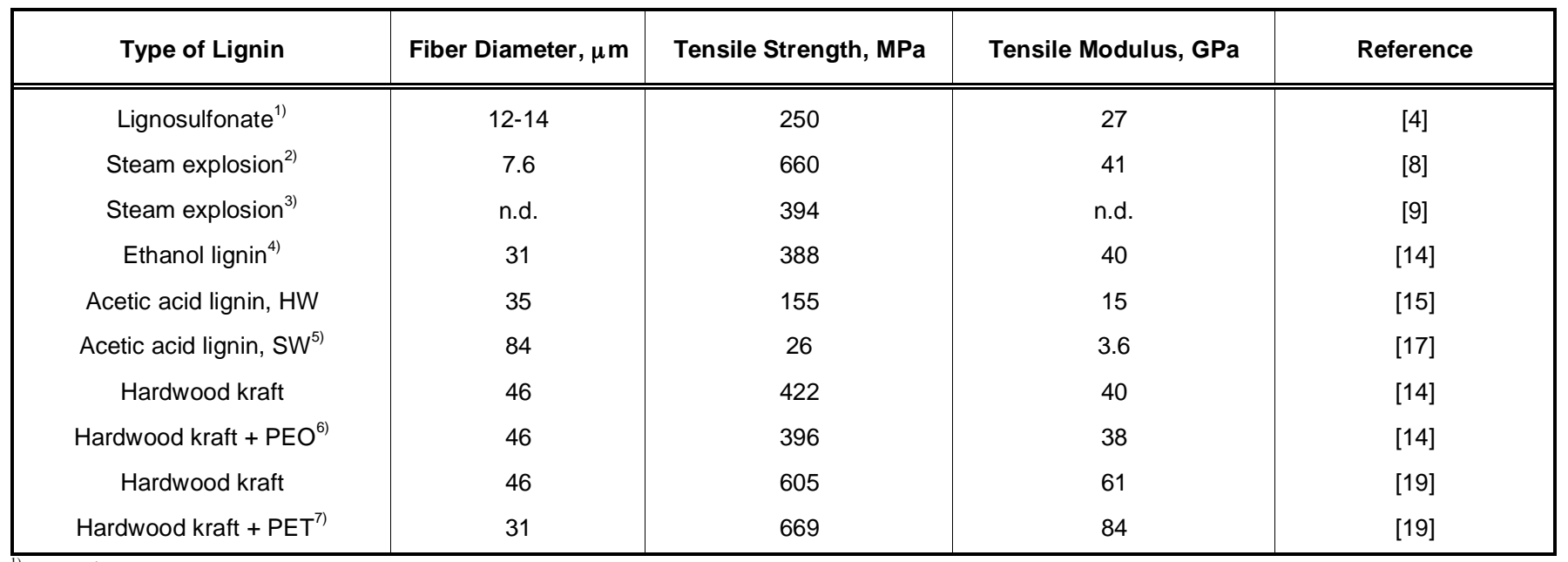

${ }^{1)}$ Kayocarbon

${ }^{2)}$ After hydrogenation

${ }^{3)}$ After phenolysis

${ }^{4)}$ Alcell lignin; 95\% lignin + 5\% PEO

${ }^{5}$ Low molecular mass fraction comprising $70 \%$ of total lignin

${ }^{6)} 5 \%$ PEO added to lignin

${ }^{7)} 5 \%$ PET added to lignin

a similar approach using softwood did not yield fusible lignin, and CF could only be obtained after fractionation of lignin to remove the highest molecular mass material. However, the strength of the resulting $\mathrm{CF}$ was inferior to that of the hardwood-based fibers (Table 1) [16, 17].

\section{Kraft Lignin}

In contrast to steam explosion lignins, kraft (and soda) lignins produced under alkaline conditions are characterized by more pronounced fragmentation of the lignin. All early attempts to produce CF from kraft lignin failed; in particular, softwood kraft lignin was reported to only produce char on heating $[16,18]$. This behavior may have been caused by the absence of a major lignin fraction with softening properties, able to act as a plasticizer. The first successfully produced $\mathrm{CF}$ from industrial kraft lignin was made from extensively purified hardwood kraft lignin [14]. To enable fiber formation, the lignin was first heat-treated under vacuum at $145^{\circ} \mathrm{C}$ for $60 \mathrm{~min}$. Volatile components in the lignin were removed and an increase in molecular mass was observed. Addition of a small amount of PEO as a plasticizer was found to improve the spinnability of the lignin; furthermore, the spinning could be done at a somewhat lower temperature compared to that for a pure lignin sample. At PEO additions $>10 \%$, self-fusion of the lignin fibers occurred. After thermo-stabilization of the lignin fibers at $250^{\circ} \mathrm{C}$ for $60 \mathrm{~min}$ in air and subsequent carbonization at $1000^{\circ} \mathrm{C}, \mathrm{CF}$ with strength properties shown in Table 1 was obtained. Without addition of PEO, but using more carefully controlled thermo-stabilization conditions, including a very slow temperature increase $\left(12^{\circ} \mathrm{C} / \mathrm{h}\right)$ of the lignin fiber to $250^{\circ} \mathrm{C}$, the subsequent carbonization resulted in improved strength characteristics (Table 1). Further improvement in strength could be obtained by adding $5 \%$ poly(ethyleneterephtalate) (PET) to the lignin prior to thermo-stabilization and carbonization (Table 1) [19].

\section{PROBLEMS WITH LIGNIN}

\section{Softening Temperature}

The softening temperature of lignin is in the range of $160-190^{\circ} \mathrm{C}$ [16-18, 20]. Consequently, successive heating and carbonization of a lignin fiber will cause self-fusion unless a stabilization reaction such as oxidation with oxygen (air), is included. Homogeneous oxidation throughout the whole cross-section of the lignin fiber requires a low rate of heating to obtain oxidation rather than cross-coupling, dehydration and other competing reactions [21]. Therefore, to become industrially feasible, the rate of modifying the lignin fiber into a thermo-setting material must be strongly increased prior to further carbonization.

\section{Purity}

The use of lignin as a precursor for $\mathrm{CF}$ requires one or more purification steps prior to spinning. A set of preliminary purity data was obtained by Oak Ridge National Laboratory in the US [22]:

- $<5 \mathrm{wt}-\%$ volatiles measured at $250^{\circ} \mathrm{C}$

- $<1000$ ppm inorganics (ash)

- <500 ppm non-melting particulates > $1 \mu \mathrm{m}$

In all of the previous reported attempts to make $\mathrm{CF}$ from lignin, extensive purification of the lignin was done prior to spinning of the lignin fiber. Low molecular mass products were eliminated by treatment of the lignin in vacuum at elevated temperature and inorganics were reduced through extensive washing with aqueous acid. In addition, organic solvents have also been used [14-16, 19]. However, only hardwood lignins have successfully resulted in $\mathrm{CF}$, as shown in Table 1. It was recently demonstrated that softwood kraft lignin can be used as a precursor of $\mathrm{CF}$ provided that a highly purified hardwood kraft lignin fraction, obtained 
through solvent extraction, was added as a plasticizer [22]. Notably, because softwood kraft pulping is much more abundant in the northern hemisphere the potential availability of softwood kraft lignin is high.

\section{Polydispersity}

It is well-known that the polydispersity of softwood kraft lignin is higher than that of hardwood. For unpurified softwood lignin, polydispersity values on the order of 4.5 and higher have been reported, whereas the corresponding values for hardwood (birch) kraft lignin are 3-4 [20, 23-25]. By solvent fractionation, about $70 \%$ of birch kraft lignin and 50 $60 \%$ of softwood kraft lignin can be isolated as highly homogeneous polymeric material with polydispersity $<2$ and a low weight average molecular mass $\left(\mathrm{M}_{\mathrm{w}}\right)$ [24, 25]. Fractionation of the black liquor with a ceramic membrane followed by precipitation with carbon dioxide and acid according to the LignoBoost principle can be used as an alternative [20]. Much more homogeneous lignin fractions were obtained in which carbohydrate impurities were virtually eliminated and the differences in polydispersity between softwood and hardwood kraft lignins negligible (Fig. 4).

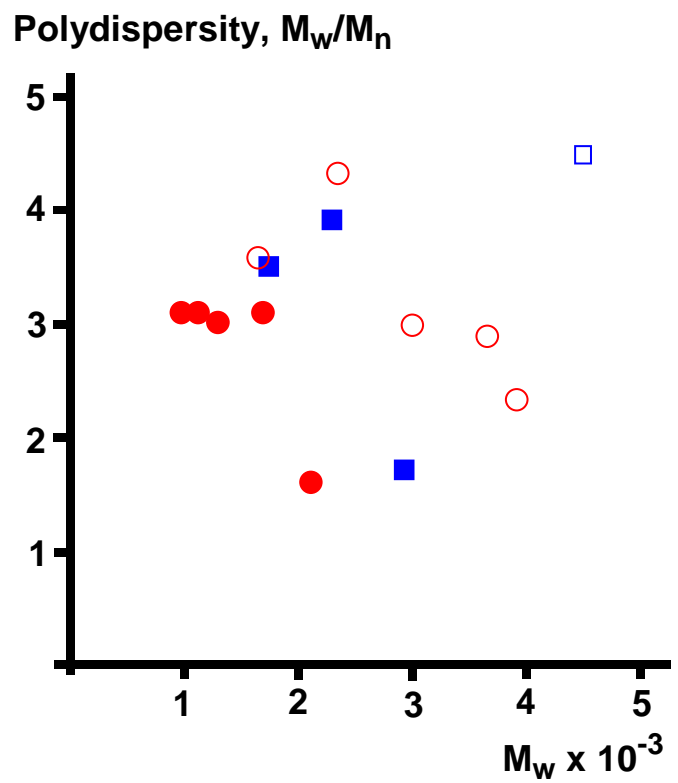

Fig. (4). Polydispersity of softwood (squares) and hardwood (circles) kraft lignins before (unfilled) and after purification (filled) by either solvent or membrane fractionation. Data from [20, 23-25].

Furthermore, fractionated kraft lignins are characterized by both a glass transition temperature $\left(\mathrm{T}_{\mathrm{g}}\right)$ and a softening temperature $\left(\mathrm{T}_{\mathrm{s}}\right)$. The latter has been ascribed to the presence of macro-Brownian motion of whole lignin molecules, so the absence of this transformation is indicative of an infusible lignin. The predominance of intact aryl-ether linkages in the lignin as well as other types of linkages able to restrict the motion of side chains has been proposed to be the major reason for the lack of $T_{s}[16]$. Hardwood kraft lignins contain higher total concentrations of intact aryl-ether linkages compared to softwood [20], yet are more easily transformed into $\mathrm{CF}$, so the presence of linear lignin fragments with syringyltype aryl-ether structures does not restrict the side-chain motion.

\section{Effects of Water}

Recently, heating a kraft lignin to temperatures around $250^{\circ} \mathrm{C}$ was shown to result in a material loss of $\sim 10-15 \%$. Except for the loss of small amounts of very volatile phenols, such as guaiacol, elimination of water seemed to be the dominant reaction [26]. Furthermore, XPS analysis of heattreated kraft lignin in air at $280^{\circ} \mathrm{C}$ or lower did not reveal an increase of olefin linkages [21]. These results implied that kraft lignin precipitated from aqueous solution may contain substantial amounts of physically adsorbed water resulting in bridging of individual lignin molecules through hydrogen linkages. Work at Oak Ridge National Laboratory has shown that purified hardwood lignins produced through the use of an aqueous isolation procedure are not melt-spinnable without addition of a plasticizing agent, such as a solventextracted lignin [22]. In other work, treatment of lignin at high temperature in the presence of water resulted in the formation of char as a predominant reaction [27] because water under such conditions acts as a strong reducing agent. If a similar reaction mechanism is operating under the conditions of lignin fiber stabilization, the presence of water may negatively influence the chemical modification reactions.

\section{CONCLUDING REMARKS}

Lignin-based $\mathrm{CF}$ is the most value-added product from a wood-based biorefinery. The prospects of making CF from (kraft) lignin are still unclear and there are many obstacles that must be overcome. Laboratory-made CF from kraft lignin has strength properties and spinnability far below those of commercial CF made from either PAN or pitch. Our knowledge about the structure of kraft lignin, the fractionation and purification of lignin, the thermal properties and the possibility of transforming lignin from thermoplastics to thermosetting polymers has considerably increased during recent years. The limited commercial availability of kraft lignins today will be changed by measures taken by the forestry industry and potentially by the automotive industry if they identify vehicle weight reduction as an option for future fuel-efficient cars. In combination with a general interest to replace petrochemical raw materials with renewable resources, kraft lignin-based $\mathrm{CF}$ is promising but requires more research.

\section{REFERENCES}

[1] Baker FS, Gallego NC, Naskar AK, Baker DA. Low-cost carbon fiber from renewable resources. Oak Ridge National Laboratory, Progress Report 2007. Available from: http://www1.eere.energy. gov/vehiclesandfuels/pdfs/lm_07/7_low-cost_carbon_fiber.pdf

[2] Axegård P, Backlund B. Ecocyclic Pulp Mill - KAM, 1996-2002, Final Report. KAM-Report A100, STFI, stockholm, sweden 2003.

[3] Öhman F, Theliander H, Tomani P, Axegård P. Method for separating lignin from black liquor. Patent WO2006031175, 2006.

[4] Fukuoka Y. Carbon fiber made from lignin (Kayacarbon). Jpn Chem Quart 1969; 5(3): 63-6.

[5] Otani S, Fukuoka Y, Igarashi B, Sasaki K. Methods for producing carbonized lignin fiber. US Patent 3461082, 1969.

[6] Robert D, Bardet M, Lapierre C, Gellerstedt G. Structural changes in aspen lignin during steam explosion treatment. Cell Chem Technol 1988; 22: 221-30.

[7] Josefsson T, Lennholm H, Gellerstedt G. Steam explosion of aspen wood. Characterisation of reaction products. Holzforschung 2002; 56: $289-97$

[8] Sudo K, Shimizu K. A new carbon fiber from lignin. J Appl Polym Sci 1992; 44: 127-34. 
[9] Sudo K, Shimizu K, Nakashima N, Yokoyama A. A new modification method of exploded lignin for the preparation of a carbon fiber precursor. J Appl Polym Sci 1993; 48: 1485-91.

[10] Shimizu K, Sudo K, Ono H, Ishihara M, Fujii T, Hishiyama S. Integrated process for total utilization of wood components by steam explosion pre-treatment. Biomass Bioenergy 1998; 14: 195203.

[11] Li J, Henriksson G, Gellerstedt G. Lignin depolymerization and its critical role for delignification of aspen wood by steam explosion. Biores Technol 2007; 98: 3061-8.

[12] Williamson PN. Repap's ALCELL process: how it works and what it offers. Pulp Pap Can 1987; 88(12): 47-9.

[13] Nimz HH, Casten R. Chemical processing of lignocellulosics. Holz Roh- Werkst 1986; 44: 207-12.

[14] Kadla JF, Kubo S, Venditti RA, Gilbert RD, Compere AL, Griffith W. Lignin-based carbon fibers for composite fiber applications. Carbon 2002; 40: 2913-20.

[15] Uraki Y, Kubo S, Nigo N, Sano Y, Sasaya T. Preparation of carbon fibers from organosolv lignin obtained by aqueous acetic acid pulping. Holzforschung 1995; 49: 343-50.

[16] Kubo S, Ishikawa N, Uraki Y, Sano Y. Preparation of lignin fibers from softwood acetic acid lignin. Relationship between fusibility and the thermal structure of lignin. Mokuzai Gakkaishi 1997; 43: 655-62.

[17] Kubo S, Uraki Y, Sano Y. Preparation of carbon fibers from softwood lignin by atmospheric acetic acid pulping. Carbon 1998; 36: 1119-24.

[18] Kubo S, Uraki Y, Sano Y. Thermomechanical analysis of isolated lignins. Holzforschung 1996; 50: 144-50
[19] Kubo S, Kadla JF. Lignin-based carbon fibers: effect of synthetic polymer blending on fiber properties. J Polym Environ 2005; 13 : 97-105.

[20] Brodin I, Sjöholm E, Gellerstedt G. Kraft lignin as feedstock for chemical products: The effects of membrane filtration. Holzforschung 2009; 63: 290-7.

[21] Braun JL, Holtman KM, Kadla JF. Lignin-based carbon fibers: Oxidative thermostabilization of kraft lignin. Carbon 2005; 43 385-94.

[22] Baker FS. Low cost carbon fiber from renewable resources. 2009 DOE Hydrogen Program and Vehicle Technologies Program Annual Merit Review and Peer Evaluation Meeting. Available from: http://www1.eere.energy.gov/vehiclesandfuels/resources/proceedin gs/printable_versions/2009_merit_review.html

[23] Glasser WG, Dave V, Frazier CE. Molecular weight distribution of (semi-)commercial lignin derivatives. J Wood Chem Technol 1993; 13: $545-59$

[24] Mörck R, Yoshida H, Kringstad KP, Hatakeyama H. Fractionation of kraft lignin by successive extraction with organic solvents. I. Functional groups, ${ }^{13} \mathrm{C}$ NMR-spectra and molecular weight distributions. Holzforschung 1986; 40 (Suppl): 51-60.

[25] Mörck R, Reimann A, Kringstad KP. Fractionation of kraft lignin by successive extraction with organic solvents. III. Fractionation of kraft lignin from birch. Holzforschung 1988; 42: 111-6.

[26] Brodin I, Sjöholm E, Gellerstedt G. The behavior of kraft lignin during thermal treatment. J Anal Appl Pyrol 2010; 87: 70-7.

[27] Kleinert M, Barth T. Production of biofuel and phenols from lignin by hydrous pyrolysis. $15^{\text {th }}$ European Biomass Conference, Berlin. Proceedings 2007; pp. 1297-301.

(C) Gellerstedt et al.; Licensee Bentham Open.

This is an open access article licensed under the terms of the Creative Commons Attribution Non-Commercial License (http://creativecommons.org/licenses/ by-nc/3.0/) which permits unrestricted, non-commercial use, distribution and reproduction in any medium, provided the work is properly cited. 